\title{
A Kinetic Study of Micronization Grinding of Dry Mica in a Planetary Ball Mill
}

\author{
Ljubiša Andrić, ${ }^{1}$ Anja Terzić, ${ }^{2}$ Zagorka Aćimović-Pavlović, ${ }^{3}$ \\ Milan Trumić, ${ }^{4}$ Milan Petrov, ${ }^{1}$ and Ljubica Pavlović ${ }^{1}$ \\ ${ }^{1}$ Institute for Technology of Nuclear and Other Mineral Raw Materials, Franchet d'Esperey Street 86, 11000 Belgrade, Serbia \\ ${ }^{2}$ Institute for Materials Testing, Vojvode Mišića Boulevard 43, 11000 Belgrade, Serbia \\ ${ }^{3}$ Faculty of Technology and Metallurgy, University of Belgrade, Karnegy Street 4, 11000 Belgrade, Serbia \\ ${ }^{4}$ Technical Faculty in Bor, University of Belgrade, Vojske Jugoslavije Street 12, 19210 Bor, Serbia
}

Correspondence should be addressed to Anja Terzić; anja.terzic@institutims.rs

Received 9 May 2013; Accepted 13 September 2013

Academic Editor: Jacques Huot

Copyright (C) 2013 Ljubiša Andrić et al. This is an open access article distributed under the Creative Commons Attribution License, which permits unrestricted use, distribution, and reproduction in any medium, provided the original work is properly cited.

\begin{abstract}
This paper presents results of the research of micronization grinding of dry mica in a planetary ball mill. Investigation was conducted in order to improve the quality and to obtain clearly defined properties and characteristics of mica powder. The micronization grinding of dry mica was performed in four time periods: 30, 60, 120, and 360 minutes. The micronized powder was investigated by means of differential thermal and thermogravimetric analyses, analysis of the degree of micronization, the specific surface area analysis, and X-ray diffraction analysis. The achieved results pointed out that dry mica micronization grinding which exceeds 360 minutes is recommended for this type of mill. However, it was also shown that the micronized mica produced by means of planetary ball mill after extra long periods of micronization grinding can pass into amorphous state.
\end{abstract}

\section{Introduction}

Mica belongs to the group of the most widespread minerals in nature. The mica minerals are present in large number of rocks such as gabbro and various sedimentary and metamorphic rocks. Chemical composition of mica minerals varies. On the other hand, morphological and physical properties are similar to various minerals. According to their chemical composition, these minerals are mainly aluminosilicates with presence of alkali and hydroxides. The main characteristic of mica minerals is remarkable stratified and complex pseudo hexagonal crystal structure. According to what was stated, mica minerals have specific physical-chemical, mineralogi$\mathrm{cal}$, and mechanical properties $[1,2]$.

The micronized mica minerals have specific applications such as condensers, insulators, plastic fillers, pearlescent pigments, coatings, polymers, equipment, and devices used in aeronautical industry [3]. Due to the characteristic color, density, reflection index, size, shape, and the structure of microparticles, the micronized minerals of mica are being used as fillers in the synthesis of the advanced materials giving them extra quality [4].

For each of the named industrial applications, it is crucial that the particles of mica minerals are reduced in size. The reduction of the average particle size of mica minerals directly affects the structure and properties of laminar silicates. In this investigation, special attention was paid to the undesirable effects such as amorphization and aggregation [5].

The most commonly applied procedure for mica minerals particle size reduction is grinding. For industrial purposes, different grinding procedures might be applied. Such procedures are dry grinding (obtained particles are in the range from $1.2 \mathrm{~mm}$ to $150 \mu \mathrm{m}$ ), wet grinding (particles are in range from 95 to $45 \mu \mathrm{m}$ ), and micronization (particles are smaller than $53 \mu \mathrm{m})$ [6]. Due to the low mill capacity $(\mathrm{kg} / \mathrm{h})$ and high energy consumption, production of particles in ultrafine size range is an extremely difficult and expensive procedure. According to these facts, the optimal $G / D$ ratio (ratio of the gyration diameter to the mill tube diameter) of planetary ball mill for ultrafine grinding was intensively studied [7]. 
Table 1: Particle size distribution and mineralogical and chemical composition of the initial mica sample, series $\left(\mathrm{M}_{0}\right)$.

\begin{tabular}{|c|c|c|c|c|c|c|c|}
\hline \multicolumn{4}{|c|}{ Particle size distribution } & \multicolumn{2}{|c|}{ Mineralogical composition } & \multicolumn{2}{|c|}{ Chemical composition } \\
\hline Size class $(\mathrm{mm})$ & Mass (\%) & Cumul. oversize (\%) & Cumul. undersize (\%) & Mineral & Content (\%) & $\begin{array}{l}\text { Oxide } \\
\text { Size cla }\end{array}$ & $\begin{array}{l}\text { Content }(\%) \\
.589+0.104)(\mathrm{mm})\end{array}$ \\
\hline $\begin{array}{l}-0.833+0.589 \\
-0.589+0.417 \\
-0.417+0.295\end{array}$ & $\begin{array}{c}0.10 \\
4.40 \\
22.50\end{array}$ & $\begin{array}{c}0.10 \\
4.50 \\
27.00\end{array}$ & $\begin{array}{c}100.00 \\
99.90 \\
95.50\end{array}$ & K-muscovite & 74.11 & $\begin{array}{c}\mathrm{SiO}_{2} \\
\mathrm{Al}_{2} \mathrm{O}_{3} \\
\mathrm{CaO}\end{array}$ & $\begin{array}{c}56.60 \\
24.50 \\
0.10\end{array}$ \\
\hline $\begin{array}{l}-0.295+0.208 \\
-0.208+0.147 \\
-0.147+0.104\end{array}$ & $\begin{array}{l}29.00 \\
23.00 \\
10.50\end{array}$ & $\begin{array}{l}56.00 \\
79.00 \\
89.50\end{array}$ & $\begin{array}{l}73.00 \\
44.00 \\
21.00\end{array}$ & Na-muscovite & 10.13 & $\begin{array}{c}\mathrm{MgO} \\
\mathrm{Na}_{2} \mathrm{O} \\
\mathrm{K}_{2} \mathrm{O}\end{array}$ & $\begin{array}{c}0.60 \\
1.90 \\
10.59\end{array}$ \\
\hline $\begin{array}{l}-0.104+0.074 \\
-0.074+0.063\end{array}$ & $\begin{array}{l}6.00 \\
1.40\end{array}$ & $\begin{array}{l}95.50 \\
96.90\end{array}$ & $\begin{array}{c}10.50 \\
4.50\end{array}$ & Quartz & 7.19 & $\begin{array}{l}\mathrm{Fe}_{2} \mathrm{O}_{3} \\
\mathrm{MnO}\end{array}$ & $\begin{array}{l}1.00 \\
0.03\end{array}$ \\
\hline $\begin{array}{l}-0.063+0.053 \\
-0.053+0.040 \\
-0.040+0.000 \\
\end{array}$ & $\begin{array}{l}1.10 \\
0.82 \\
1.18 \\
\end{array}$ & $\begin{array}{c}98.00 \\
98.82 \\
100.00 \\
\end{array}$ & $\begin{array}{l}3.10 \\
2.00 \\
1.18 \\
\end{array}$ & Feldspar & 3.74 & $\begin{array}{c}\mathrm{TiO}_{2} \\
\mathrm{P} \\
\mathrm{S} \\
\end{array}$ & $\begin{array}{l}0.18 \\
0.40 \\
0.40 \\
\end{array}$ \\
\hline Total & 100.00 & - & - & Total & 95.17 & LoI & 3.70 \\
\hline
\end{tabular}

Furthermore, the effect of high-energy ball milling (HEBM) technique on particle size reduction of mica minerals was widely studied. The HEBM technique pointed out to the significant changes in the size, structure, and morphology of the minerals. All these changes were followed by the change of the physicochemical properties of the investigated material [8]. Application of the ultrasound analysis enables detection of micron and submicron particles of the minerals. At the same time, formations and characterization of these particles can be explained. According to this, minerals of mica (muscovite, vermiculite, and biotite) were subjected to ultrasound analysis $[9,10]$.

Previous investigations of the kinetic of mica micronization grinding showed that the type of mill and the mode of mechanical energy transfer onto the mica particles have more significant effect than the micronization grinding time. This effect depends on operating conditions, device power, weight of grinding media, filling rate, capacity, duration of micronization grinding, presence of additives, and so forth [11-14].

The achieved results will serve for defining the correlation between technological parameters, structure, and required properties of mica powder. At the same time, the results could be used in the process of application of mica powder in the synthesis of advanced materials. The aim of this investigation was to improve the quality of mica powders with accurately and strictly defined properties and characteristics (physicomechanical, physicochemical, and mineralogical characteristics) through micronization grinding in planetary ball mill.

\section{Experimental}

A flotation mica concentrate $\left(\mathrm{KAl}_{2}\left(\mathrm{Si}_{3} \mathrm{Al}\right) \mathrm{O}_{10}(\mathrm{OH}, \mathrm{F})_{2}\right)$ obtained by the technological processing of white granites from the beds "Samoljica," Bujanovac (South Serbia) was used as the initial material in the investigation. The basic physicochemical characteristics of mica concentrate were determined by standard laboratory procedure. The following values were obtained: density $\tau=3.00\left(\mathrm{~g} / \mathrm{cm}^{3}\right)$, humidity $W_{1}=10.00(\%), W_{2}=0.50$ (\%) (after drying), and volume density $\Delta=1.17\left(\mathrm{~g} / \mathrm{cm}^{3}\right)$. Particle size distribution and chemical and mineralogical composition of the initial mica sample $\left(\mathrm{M}_{0}\right)$ are presented in Table 1 .

The micronization grinding was conducted in the planetary ball mill-Planetary Ball Mill PM 100 CM (Retsch $\mathrm{GmbH}$, Germany). The PM $100 \mathrm{CM}$ is a benchtop model with one grinding station. It operates in centrifugal mode, which leads to a more gentle size reduction process with less abrasion. The extremely high centrifugal forces of the mill result in very high pulverization energy and therefore short grinding times. This ball mill is suitable for long-term trials and continuous use, and it has two different grinding modes (dry and wet). Material feed size is $<10 \mathrm{~mm}$, and final fineness is $<1 \mu \mathrm{m}$ and for colloidal grinding $<0.1 \mu \mathrm{m}$. Batch size is max. $1 \times$ $220 \mathrm{~mL}$ and max. $2 \times 20 \mathrm{~mL}$ with stacked grinding. Material used for grinding tools is stainless steel, and grinding jar sizes are $50 \mathrm{~mL} / 80 \mathrm{~mL}$. The grinding jar is arranged eccentrically on the sun wheel of the planetary ball mill. The direction of movement of the sun wheel is opposite to that of the grinding jars at the ratio 1:-1. The grinding balls in the grinding jars are subjected to superimposed rotational movements, the socalled Coriolis forces. The difference in speeds between the balls and grinding jars produces an interaction between frictional and impact forces, which releases high dynamic energies. The interplay between these forces produces the high and very effective degree of size reduction of the planetary ball mill. Planetary mills with a single grinding station require a counterweight for balancing purposes. In the Ball Mill PM $100 \mathrm{CM}$, this counterweight can be adjusted on an inclined guide rail. In this way the different heights of the centers of gravity of differently-sized grinding jars can be compensated in order to avoid disturbing oscillations of the machine. The PM 100 CM operates with a speed ratio of $1:-1$ (centrifugal mode). The centrifugal forces produce the rotation movement of the sample and the grinding balls against the inner wall of the grinding jar. The size reduction of the particles is induced primarily by pressure and friction.

The micronization grinding was carried out in four time periods: $30,60,120$, and 360 minutes, the series designated $\mathrm{M}_{1}, \mathrm{M}_{2}, \mathrm{M}_{3}$, and $\mathrm{M}_{4}$, respectively. 
TABLE 2: The results of changes in the mean diameter and specific surface area of the particles.

\begin{tabular}{|c|c|c|c|}
\hline Sample & Duration of grinding (min) & Mean diameter $(\mu \mathrm{m})$ & Specific surface area $\left(\mathrm{cm}^{2} / \mathrm{g}\right)$ \\
\hline $\mathrm{M}_{1}$ & 30 & 67.19 & 2.009 \\
\hline $\mathrm{M}_{2}$ & 60 & 89.60 & 1.289 \\
\hline $\mathrm{M}_{3}$ & 120 & 79.81 & 1.664 \\
\hline $\mathrm{M}_{4}$ & 360 & 32.59 & 4.740 \\
\hline
\end{tabular}

The kinetic of the process was analyzed through the changes of the particle size distribution and the specific surface area caused by duration of micronization grinding. The analyses of micronized products were conducted using different instrumental techniques. For detailed powder characterization (determination of the particle size distribution, the mean diameter, and specific surface area of the particles) "Coulter-Electronics-Coulter Multisizer" (Beckman Coulter, Inc., Switzerland) was used. For defining of the thermal and thermogravimetric characteristics of the samples a simultaneous thermal analyzer "STA-409 EP" (NETZSCHGerätebau GmbH, Germany) was used. X-ray structural analysis was utilized for the observation of the phase composition. For this purpose, an X-ray diffractometer "PW-170" (Philips, The Netherlands) was used. The qualitative mineralogical analysis was examined by immersion method (immersion ksilol). For this purpose, polarized microscope with light linkage and possibility of objective enlargement from 10 to 50 times was applied.

The analysis of the kinetic of the process, explained by the following equations, describes mathematical dependence of relevant values related to changes in the particles size distribution and the specific surface area of mica powder. The changes in the particle size distribution, during the dry micronization grinding are described by the following equation:

$$
\frac{d_{\infty}-d}{d_{\infty}-d_{0}}=\exp ^{-k t},
$$

where $d_{\infty}$ is maximal value of mean diameter of the particles during micronization grinding; $d_{0}$ is initial value of mean diameter of particles after $(t)$ minutes of micronization grinding; and $k$ is kinetic rate of the micronization grinding [11].

The changes in the specific surface area of mica powder are described by the following equation:

$$
S=S_{\infty}-\left(S_{\infty}-S_{0}\right) \exp ^{-k t},
$$

where $S_{\infty}$ is limited value of the specific surface area of micronized mica product; $S_{0}$ is initial value of the specific surface area after $(t)$ minutes of micronization grinding; and $k$ is kinetic rate of the micronization grinding [11].

\section{Results and Discussion}

The results of changes in the mean diameter and specific surface area of the micronized mica samples in series $M_{1}, M_{2}$, $\mathrm{M}_{3}$, and $\mathrm{M}_{4}$ are given in Table 2 .

The mean diameter and subsequently the specific surface area are first increasing with the increasing of the duration of
TABLE 3: The characteristic parameters of the micronized products.

\begin{tabular}{lc}
\hline Parameter & Value \\
\hline$d_{\infty}$ & $32.59 \mu \mathrm{m}$ \\
$d_{0}$ & $109.70 \mu \mathrm{m}$ \\
$k$ & $0.02 \mathrm{~min}^{-1}$ \\
$S_{\infty}$ & $4.740 \mathrm{~cm}^{2} / \mathrm{g}$ \\
$S_{0}$ & $1.208 \mathrm{~cm}^{2} / \mathrm{g}$ \\
$k$ & $8.5 \times 10^{-3} \mathrm{~min}^{-1}$ \\
\hline
\end{tabular}

the micronization procedure. Maximum for mean diameter is reached after 60 minutes of micronization. Afterwards, the value of the mean diameter decreases, and it reaches its minimal value for 360 minutes long grinding. Longer grindings would cause further reduction in the mean diameter of the mica particles; however, the attention should be paid to the possibility of the amorphization of the particles.

Based on (1) and (2), the characteristic parameters of micronized products are derived. In accordance with derived parameters, changes in the particle size distribution and specific surface area were analyzed. The characteristic parameters of micronized mica samples are presented in Table 3.

In accordance with the data obtained by the micronization grinding of dry mica in planetary ball mill, it can be seen that the best micronization effect could be achieved during time period over 360 minutes. Significant changes in the mean diameter and specific surface area of the dust particles are not noticed. In addition, a higher level of micronization grinding is observed in the series $\mathrm{M}_{4}$. Based on this, detailed examination of the micronized mica sample, series $\mathrm{M}_{4}$, was carried out.

In order to explain the influence of the micronization grinding procedure on the structure and characteristics of mica, specific analyses were performed before and after the procedure: $\mathrm{X}$-ray powder diffraction analysis (XRD); differential thermal analysis (DTA) and thermogravimetric analysis (TG); and scanning electron microscopy (SEM).

The results of the X-ray analysis of the initial mica sample (series $\mathrm{M}_{0}$ ) and micronized mica sample (series $\mathrm{M}_{4}$ ) are shown in Figures 1 and 2, respectively.

Mineralogical phase changes as well as the variations in crystallinity occurring in mica samples were tracked by means of XRD analysis. In Figures 1 and 2, the diffractograms of mica samples before and after micronization grinding are given. It was noticed that changes in the crystal structure of mica appeared within 30 minutes of the micronization process. However, the mechanical reduction of the original particles of investigated mineral appears to have reached a limit 


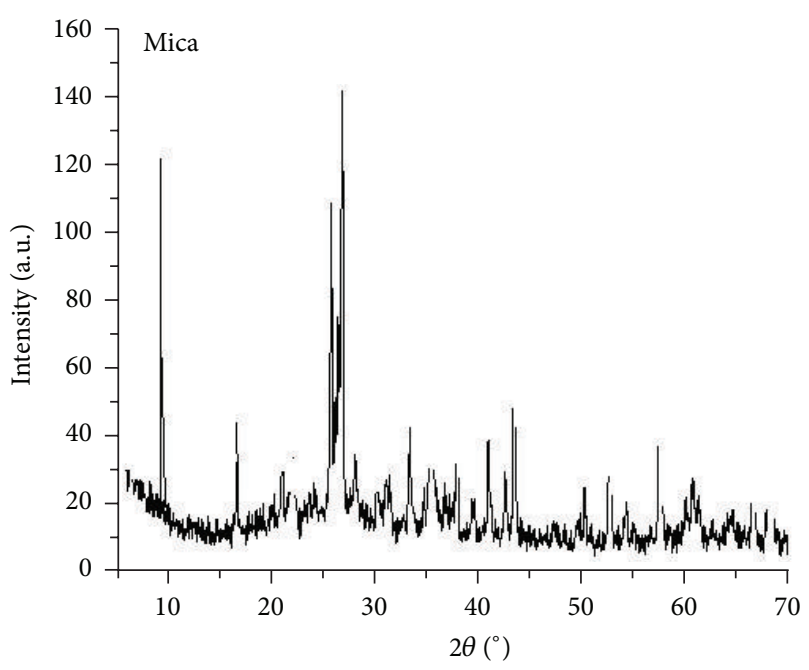

FIGURE 1: Diffractogram of the initial mica sample, series $M_{0}$.

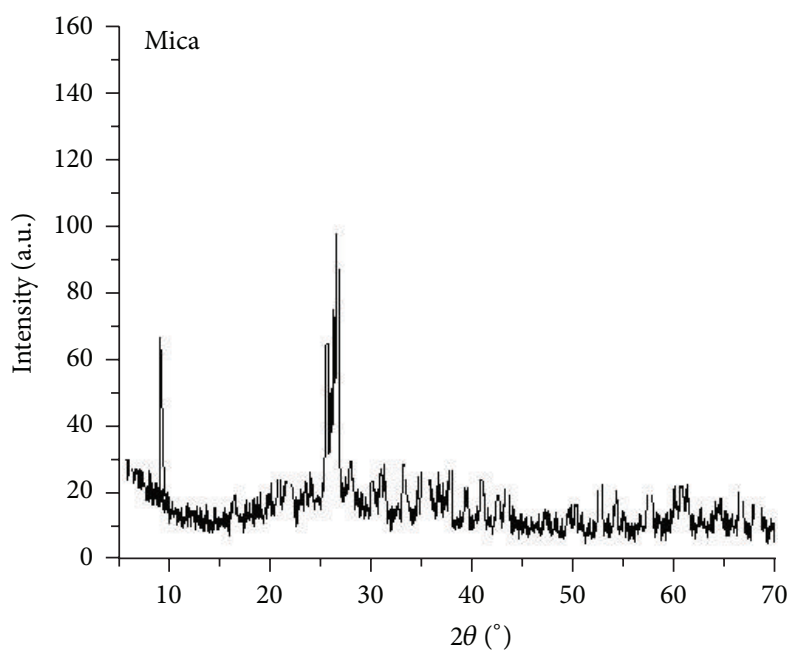

Figure 2: Diffractogram of the micronized mica sample, series $\mathrm{M}_{4}$.

at 360 minutes grinding time, and longer grinding times might produce contra effect, an increase in particle size and amorphization [12]. From Figures 1 and 2, it can be seen that the duration of the micronization influences the crystallinity of mica samples; that is, the level of crystallinity is decreasing with the increasing of the duration of micronization grinding. Namely, micronization makes the structure disordered and generates crystal lattice defects or other metastable forms $[12,13]$. The micronization grinding treatment might promote the amorphization of treated material, noticeable change of the microstructure, size and shape of particles, and so forth [14]. The appearances of the minimal intensities in diagram (Figure 2) indicate degradation of crystal lattice in the micronized mica sample, series $\mathrm{M}_{4}$ [15].

Thermal characteristics of the processes taking place during mica thermal treatment from 20 to $1100^{\circ} \mathrm{C}$ were identified by means of DTA method. Results of DTA and TG analyses of the initial mica sample (series $\mathrm{M}_{0}$ ) and micronized mica

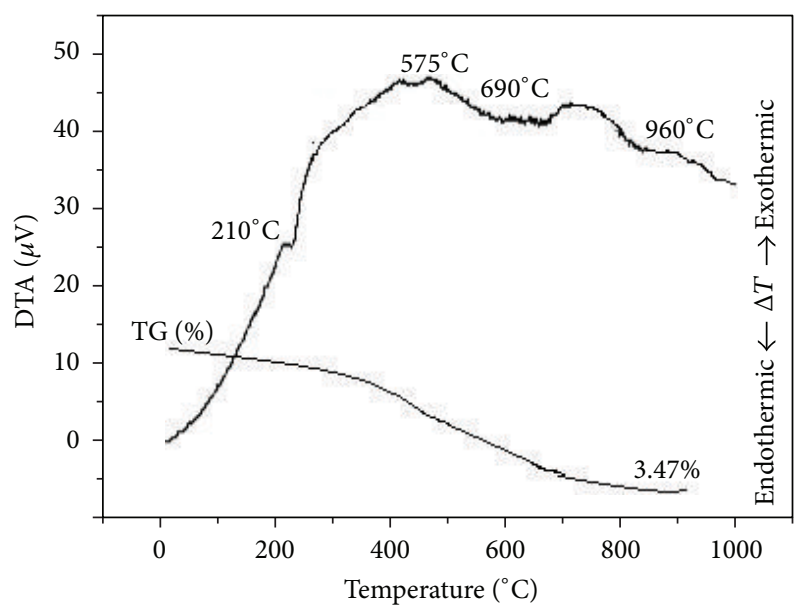

FIgure 3: DTA and TGA results of the initial mica sample, series $\mathrm{M}_{0}$.

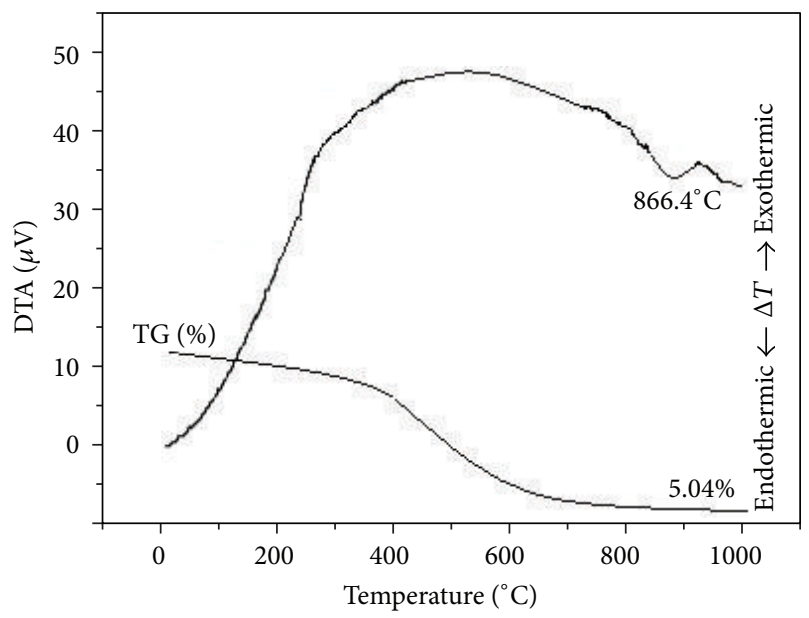

FIGURE 4: DTA and TGA results of the micronized mica sample, series $\mathrm{M}_{4}$.

sample (series $\mathrm{M}_{4}$ ) are shown in Figures 3 and 4, respectively $[11,15]$.

The DTA curve for mica sample $\mathrm{M}_{0}$ is given in Figure 3. All significant peaks are exothermic, and they are showing at approximately $210^{\circ} \mathrm{C}, 575^{\circ} \mathrm{C}, 690^{\circ} \mathrm{C}$, and $960^{\circ} \mathrm{C}$. According to the data obtained by means of the chemical analysis (Table 1), it can be concluded that the initial sample $\left(\mathrm{M}_{0}\right)$ was crystalline mica (muscovite) which was also registered by the endothermic effect at $575^{\circ} \mathrm{C}$ in Figure 3. Melting of the mica samples is not recorded up to the temperature of $1100^{\circ} \mathrm{C}$ which contributes to good refractory characteristics of the mica as raw component material. DTA curve of micronized mica sample $\mathrm{M}_{4}$ (after 360 minutes of grinding) is slightly changed in comparison with the DTA curve recorded before micronization treatment (Figure 4). Namely, the curve is smoother, the exothermic peaks disappeared, and new endothermic peak is noticed at $866^{\circ} \mathrm{C}$. This effect corresponds to dehydroxylication. Melting was not noticed, and thus, it can 


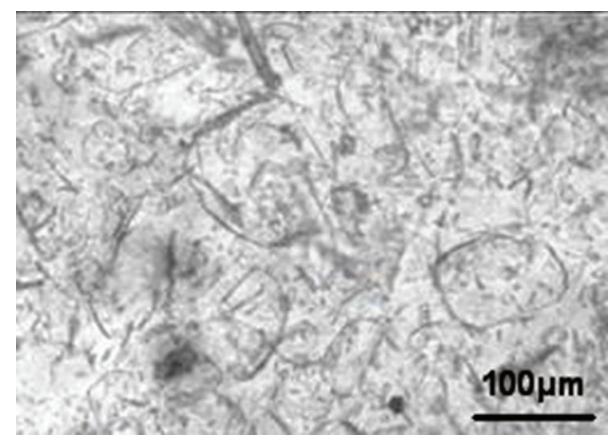

FIgURE 5: Microphotography of the initial mica sample, series $M_{0}$.

be concluded that micronization does not initiate decreasing of the melting point for mica.

In addition, in Figure 3, the TGA results show that the sample gradually lost weight during heating up to $1000^{\circ} \mathrm{C}$. The total weight loss was $3.47 \%$. Analyzing achieved results of the micronized sample, series $\mathrm{M}_{4}$ it was concluded that the total weight loss was $5.04 \%$. The comparison of the results presented in Figures 3 and 4 indicates that the difference in the total weight loss was about $1.57 \%$. This difference could be explained by appearance of wet absorption on the surface molecules [15].

The results of the qualitative mineralogical analysis of the initial sample (series $\mathrm{M}_{0}$ ) and micronized sample (series $\mathrm{M}_{4}$ ) are shown in Figures 5 and 6, respectively. Typical mica (muscovite) nonactivated particles are thin and wide, having a more plate-like form [16]. It can be seen that after micronization, mica particles gained a pseudo hexagonal crystal form [17]. The particles maintained its layered structure, but the size of particles is reduced. Other more significant changes were not noticed.

\section{Conclusion}

The results obtained in this investigation of the kinetics of micronization grinding in the planetary ball mill are as follows.

(i) The efficient micronization grinding of dry mica in planetary ball mill could be achieved in and over 360 minutes time period.

(ii) The micronization grinding of dry mica is recommended to be performed in longer periods, but special attention should be paid the possibility of micronized mica passing into the amorphous state.

(iii) The mode of mechanical energy transfer onto the mica particles plays the key role for the efficient micronization grinding of dry mica in planetary ball mill. Due to this fact, small changes in the structure and properties of mica were achieved.

(iv) According to what was stated, the micronization grinding of dry mica requires a higher consumption of energy. Due to this fact, planetary ball mill is an uneconomic device for the efficient micronization

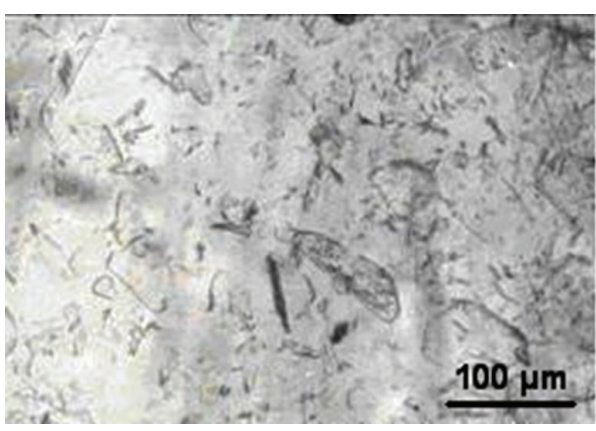

FIGURE 6: Microphotography of the micronized mica sample, series $\mathrm{M}_{4}$.

grinding of dry mica. However, the contribution and interpretation that occurred during micronization grinding of dry mica in planetary ball mill could be used for obtaining powder materials of a priori defined properties and fillers.

\section{Acknowledgments}

This investigation was supported and funded by Ministry of Education, Science and Technological Development of the Republic of Serbia, and it was conducted under the projects: $33007,34006,172057$, and 45008.

\section{References}

[1] S. Janjić and P. Ristić, Mineralogija, Naučna Knjiga, Belgrade, Serbia, 1995.

[2] S. Milošević, Domestic Nonmetalic Mineral Raw Materials for Commercial Use, Institute for Technology of Nuclear and Other Minerals Raw Materials, Belgrade, Serbia, 2000.

[3] S. G. Barlow, "Influence of time and temperature on reactions and transformations of muscovite mica," British Ceramic Transactions, vol. 98, no. 3, pp. 122-126, 1999.

[4] K. Cheng, J. Wan, and K. Liang, "Enhanced mechanical properties of oriented mica glass-ceramics," Materials Letters, vol. 39, no. 6, pp. 350-353, 1999.

[5] J. L. Pérez-Rodríguez, A. Wiewióra, J. Drapala, and L. A. PérezMaqueda, "The effect of sonication on dioctahedral and trioctahedral micas," Ultrasonics Sonochemistry, vol. 13, pp. 61-67, 2006.

[6] L. A. Pérez-Maqueda, J. M. Blanes, J. Pascual, and J. L. PérezRodríguez, "The influence of sonication on the thermal behavior of muscovite and biotite," Journal of the European Ceramic Society, vol. 24, no. 9, pp. 2793-2801, 2004.

[7] H. Cho, H. Lee, and Y. Lee, "Some breakage characteristics of ultra-fine wet grinding with a centrifugal mill," International Journal of Mineral Processing, vol. 78, no. 4, pp. 250-261, 2006.

[8] N. Vdovic, I. Jurina, S. D. Škapin, and I. Sondi, "The surface properties of clay minerals modified by intensive dry millingrevisited," Applied Clay Science, vol. 48, no. 4, pp. 575-580, 2010.

[9] L. A. Pérez-Maqueda, O. B. Caneo, J. Poyato, and J. L. PérezRodríguez, "Preparation and characterization of micron and submicron-sized vermiculite," Physics and Chemistry of Minerals, vol. 28, pp. 61-66, 2001. 
[10] L. A. Pérez-Maqueda, F. Franco, M. A. Avilés, J. Poyato, and J. L. Pérez-Rodríguez, "Effect of sonication on particle-size distribution in natural muscovite and biotite," Clays and Clay Minerals, vol. 51, pp. 701-708, 2003.

[11] Lj. Andrić, Investigation of the Kinetics of Dry Micronization of Mica in Ultra-Centifugal Mill with a Peipheral Comminution Path, Faculty of Mining and Geology, Belgrade, Serbia, 1992.

[12] P. Baláž and M. Achimovičová, "Mechano-chemical leaching in hydrometallurgy of complex sulphides," Hydrometallurgy, vol. 84, no. 1-2, pp. 60-68, 2006.

[13] V. Balek, L. A. Pérez-Maqueda, J. Poyato et al., "Effect of grinding on thermal reactivity of ceramic clay minerals," Journal of Thermal Analysis and Calorimetry, vol. 88, no. 1, pp. 87-91, 2007.

[14] V. Balek, J. L. Pérez-Rodríguez, L. A. Pérez-Maqueda, J. Šubrt, and J. Poyato, "Therma behavior of ground vermiculite," Journal of Thermal Analysis and Calorimetry, vol. 88, no. 3, pp. 819-823, 2007.

[15] L. Andrić, M. Petrov, V. Milošević, and S. Mihajlović, "Operating technique of mills in the process of micronization milling of alumina," Journal of Mining and Mateallurgy A, vol. 41, no. 1-4, pp. 27-43, 2005.

[16] J. Yvon, F. Villieras, and L. Michot, "Effect of different dry grinding procedures on the immersion heat of talc and chlorite," Journal of Mining and Metallurgy A, vol. 41, pp. 1-9, 2005.

[17] M. Holopainen, M. Hirvonen, H. Komulainen, and M. Klockars, "Mica dust-induced TNF $\alpha$ production in mouse macrophages in vitro," Annals of Occupational Hygiene, vol. 46, pp. 300$303,2002$. 

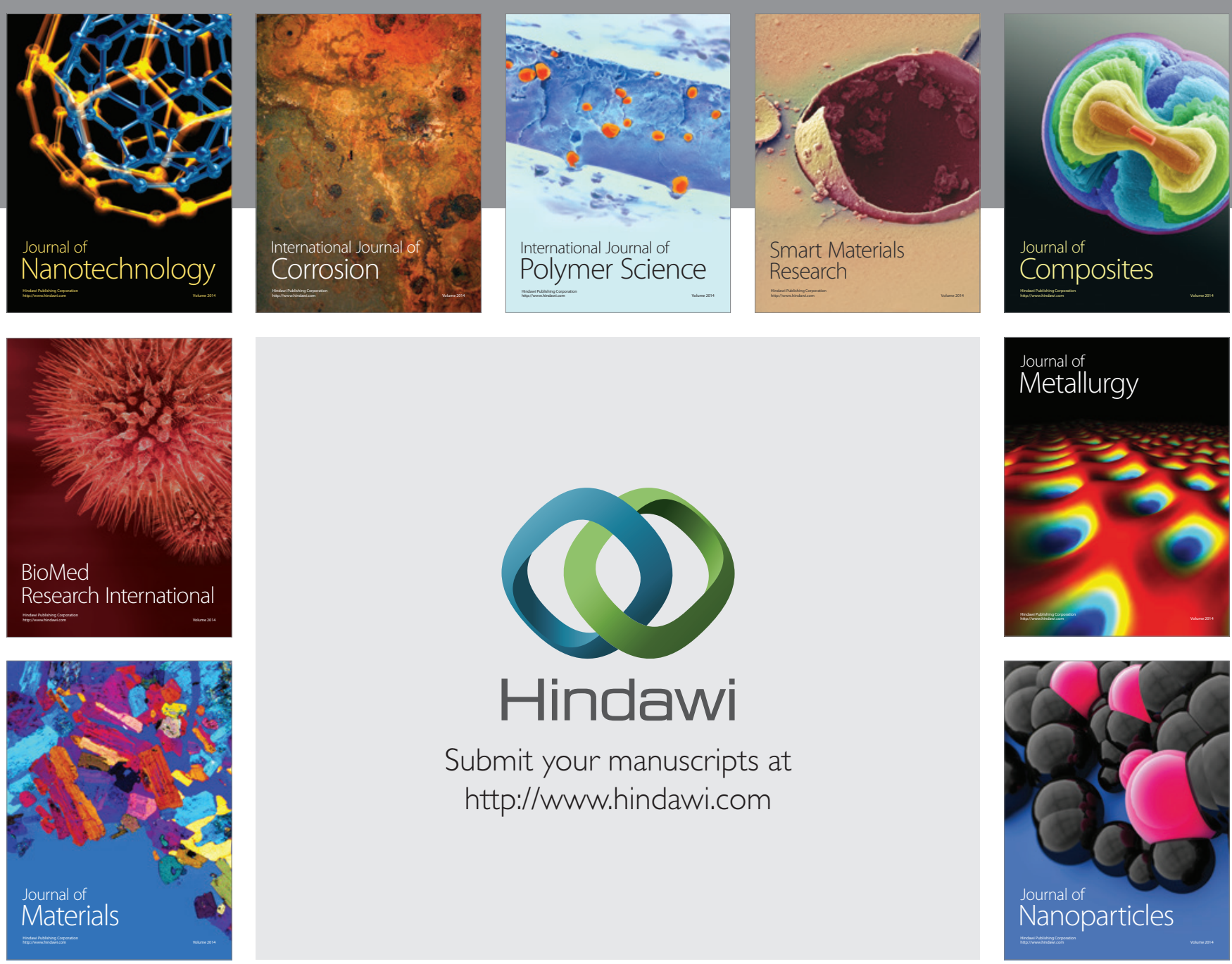

Submit your manuscripts at http://www.hindawi.com
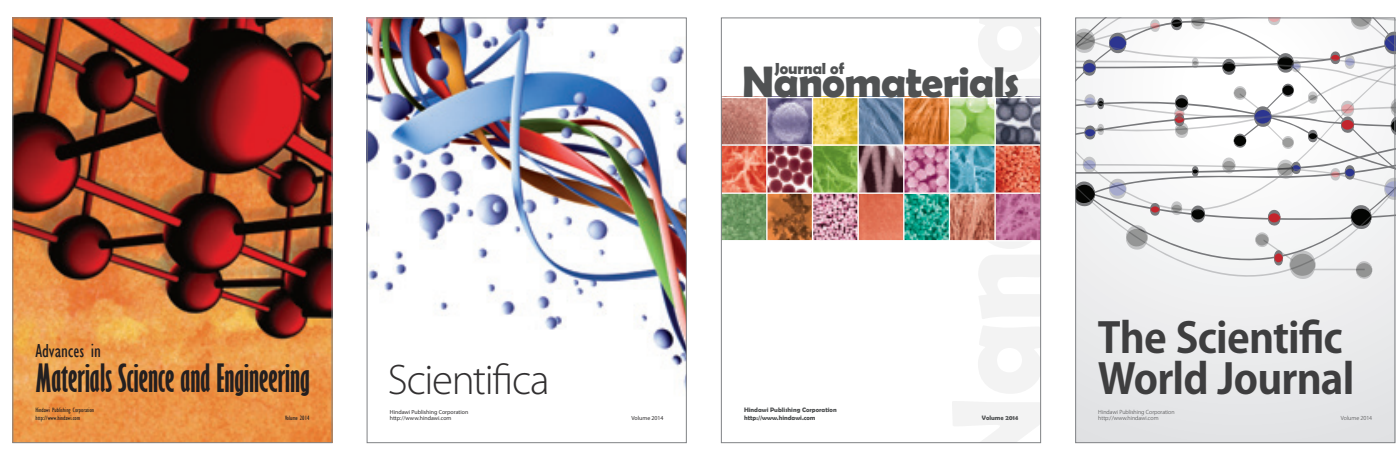

\section{The Scientific World Journal}
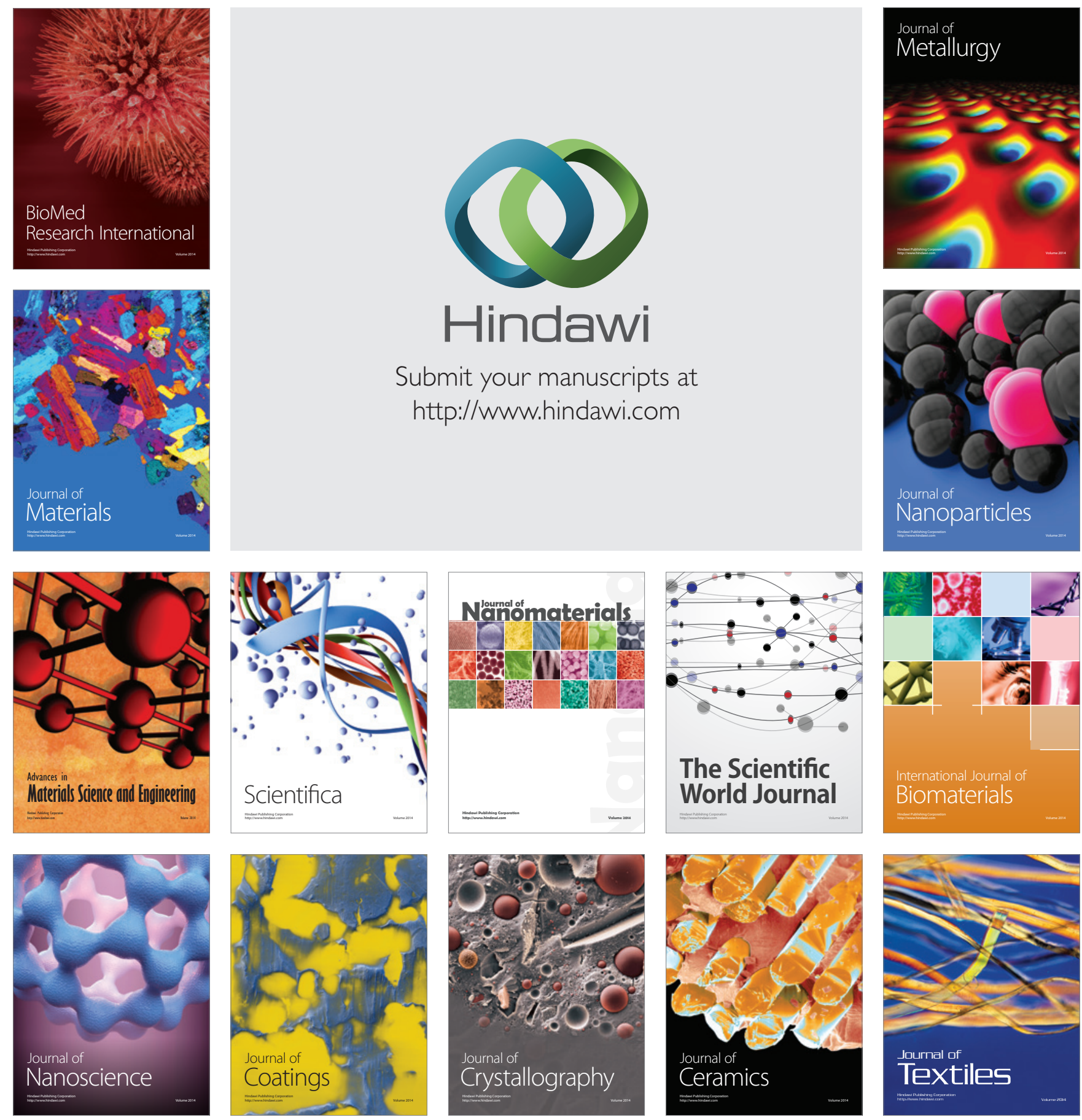